\title{
Synthesis of Poly(5-amino-1,4-dihydroxy-9,10-anthraquinone) by Potential Sweep Method
}

\author{
Yoichi MORI, ${ }^{*}$ Shoichiro IKEDA, and Masunobu MAEDA
}

\begin{abstract}
Department of Applied Chemistry, Faculty of Engineering, Nagoya Institute of Technology (Gokiso-cho, Showa-ku, Nagoya 466-8555, Japan)
\end{abstract}

Received May 12, 2003 ; Accepted October 6, 2003

\begin{abstract}
The electropolymerization of 5-amino-1,4-dihydroxy-9,10-anthraquinone (5-aminoquinizarine: 5 -AQ) in acetonitrile solution containing $0.1 \mathrm{M}$ of tetraethylammonium perchlorate (TEAP) results in the formation of the polymer films, which are adherent on Pt electrodes. FTIR studies indicate that the aromatic amine groups take part in the polymerization process. This polymer film is electroactive in acetonitrile solution containing $0.1 \mathrm{M}$ TEAP, and also has good cycleability more than 50 cycles in the potential range between 0.0 and $+1.0 \mathrm{~V} \mathrm{vs}$. $\mathrm{Ag} / \mathrm{AgCl}$. Scanning the potential between 0.0 and $+1.4 \mathrm{~V}$ vs. $\mathrm{Ag} / \mathrm{AgCl}$ results in the polymer deterioration gradually. In the negative region than $0 \mathrm{~V}$ vs. $\mathrm{Ag} / \mathrm{AgCl}$ the polymer is eliminated from the Pt electrode.
\end{abstract}

Key Words : 5-amino-1,4-dihydroxy-9,10-anthraquinone, Electroactivity, Polymer Film

\section{Introduction}

The synthesis of modified electrodes has received considerable attention owing to their wide application. Among the methods to modify the electrodes, the coating electrodes with organic polymer have been widely employed. In general, however, most redox reactions in organic chemistry are irreversible, because the formation and cleavage of covalent bonds containing at least one $\mathrm{C}$ atom are strongly irreversible steps. For reversible organic redox reactions, exclusive formation and cleavage of $\mathrm{O}-\mathrm{H}, \mathrm{N}-\mathrm{H}, \mathrm{S}-\mathrm{H}$, or S-S bonds is a necessary precondition pointed out by v. Stackelberg. ${ }^{1)}$

Hydroquinone/benzoquinone redox system is a prominent example well known as a reversible organic redox system. But these redox active molecules are soluble in conventional solvents. To utilize them for redox reactions on electrodes, it is necessary to hold hydroquinone/benzoquinone parts on the electrodes. One of such examples, a composite electrode which consists of polyaniline and benzoquinone has been reported. ${ }^{2}$ However, quinones are away from composite electrode during redox cycles, and then the performance deterioration occurs. It seems more effective that quinones are immobilized than be simply hold on them. The examples that immobilize quinones, there are to the polymer chains are already synthesized and studied their electrochemical property. ${ }^{3-7)}$<smiles>Nc1cccc2c1C(=O)c1c(O)ccc(O)c1C2=O</smiles>

Scheme 1 5-aminoquinizarin: 5-AQ.
The polymers having both redox activity and electronic conductivity are applicable to various devices such as electrochromic devices, electrocatalysis, batteries and supercapacitors.

Quinizarine is important dyestuff and also raw materials of them. The molecule has two adjacent quinone units, and also being used for detecting various kind of metal ions. It is very interesting to employ quinizarine derivative to application for electrochemical devices. Various aromatic amine monomers are electropolymerized to various conductive polymers. ${ }^{16)}$ But there is very few kind of the polymer which has hydroquinone/quinone unit in their structure. In this work, we have attempted to synthesize a new conductive polymer that has quinizarine unit belonging to the structure by electropolymerization with aromatic monomer, namely 5-aminoquinizarine: $5-\mathrm{AQ}$ as shown in Scheme 1. About 5-AQ monomer concerned, this is the first polymer synthesized from it.

\section{1 Chemicals}

\section{Experimental}

5 -amino- 1,4 -dihydroxy- 9,10 -anthraquinone

$(5-$ aminoquinizarine : 5 -AQ)

$\mathrm{FeSO}_{4} \cdot 7 \mathrm{H}_{2} \mathrm{O}$ (Nacalai tesque) $(50 \mathrm{~g})$ was dissolved in the mixture of acetic acid (Wako) $(100 \mathrm{ml})$ and concentrated hydrochloric acid (Kishida) $(100 \mathrm{ml})$. When the solution turned to transparent, 5-nitro-1,4-dihydroxy-9,10anthraquinone $^{8)}(5.0 \mathrm{~g})$ was added and refluxed with stirring for 4 hours. The mixture was poured to water, the precipitate was recrystallized from concentrated hydrochloric acid. The structure was confirmed by H-NMR, IR, and mass spectroscopy. IR (KBr) $\vee \mathrm{cm}^{-1}: 1607(\mathrm{C}=$ O); 3341 and $3465\left(\mathrm{NH}_{2}\right)$. ${ }^{1} \mathrm{H}-\mathrm{NMR}$ (DMSO-d $\left.\mathrm{d}_{6}\right) \delta \mathrm{ppm}$ : 13.09 $(1 \mathrm{H}) ; 12.83(1 \mathrm{H}) ; 8.1(2 \mathrm{H}$, broad); 7.52 $(1 \mathrm{H}) ; 7.41(1$ H); $7.30(1 \mathrm{H}) ; 7.26(1 \mathrm{H}) ; 7.20(1 \mathrm{H})$. MASS (EI): 255 . 


\section{Solvent}

HPLC grade acetonitrile (Kishida) was used without further purification.

\section{2 Electrochemical measurements}

A standard three-electrode, two-compartment electrochemical cell was used for all the electrochemical experiments. Electrochemical measurements were performed with a HA-303 potentiostat (HOKUTO) connected to a HB-105 functiongenerator (HOKUTO). The sample solutions were degassed with nitrogen for $30 \mathrm{~min}$. The working electrode was a Pt plate $(5 \mathrm{~mm} \times 5 \mathrm{~mm})$. The working and counter electrodes were annealed on oxygen and methane flame before experiments. The reference electrode was $\mathrm{Ag} / \mathrm{AgCl}$ electrode.

\section{3 FTIR spectroscopy}

The $\mathrm{KBr}$ disk method was used for the monomer. Ex situ external reflection method was used for the polymers electrodeposited on Pt electrodes.

\section{1 FTIR analysis}

\section{Results and Discussion}

Figure 1 shows FTIR spectra of polymers and monomer: (a) poly (5-AQ) film grown by sweep in the potential range of 0.0 to $+1.4 \mathrm{~V}$ (polymer $\mathrm{A}$ ); (b) poly (5-AQ) film grown by sweep in the potential range of 0.0 to $+2.0 \mathrm{~V}$ (polymer B); (c) 5-AQ monomer. The spectra of polymer A (a) and polymer B (b) were obtained by reflection mode for electrodeposited polymers on platinum plate electrodes, and the spectrum of 5-AQ monomer (c) was obtained by transmission mode of $\mathrm{KBr}$ disk method.

In 5-AQ monomer spectrum (c), two sharp bands were observed at 3465 and $3341 \mathrm{~cm}$, which were attributed to $\mathrm{N}-\mathrm{H}$ asymmetric and $\mathrm{N}-\mathrm{H}$ symmetric stretching vibrations of primary amino group, respectively. In poly (5-AQ) spectra $(a, b)$, instead of the disappearance of these two bands, another broad peaks appeared around $3600 \mathrm{~cm}^{-1}$. That corresponds to $\mathrm{N}-\mathrm{H}$ stretching vibration of secondary amine. Therefore, it is suggested that the $\mathrm{NH}_{2}$ groups participate in polymerization. ${ }^{6,10)}$

In the monomer spectrum (c), the sharp band at 783 $\mathrm{cm}^{-1}$ are attributed to $\mathrm{C}-\mathrm{H}$ out-of-plane vibrations of three

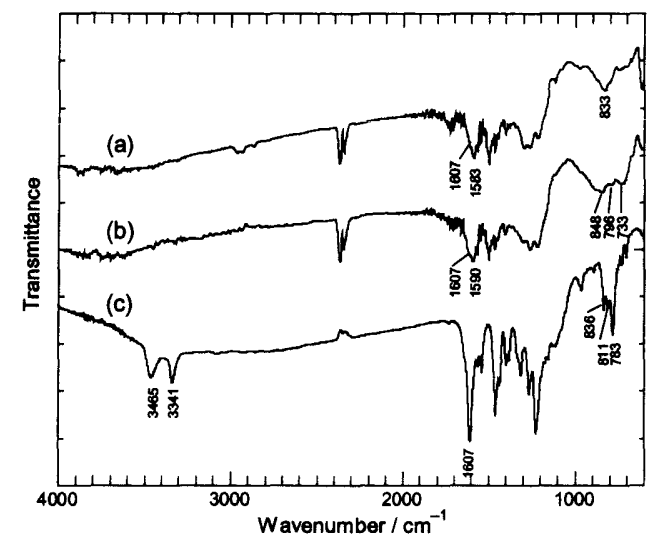

Fig. 1 FTIR spectra of (a) polymer A grown by sweep in the potential range of 0.0 to $+1.4 \mathrm{~V}$; (b) polymer $\mathrm{B}$ grown by sweep in the potential range of 0.0 to $+2.0 \mathrm{~V}$; (c) monomeric 5-AQ. adjacent hydrogen atoms ${ }^{15)}$ on the benzene ring containing amino group. This band disappeared in the spectrum of polymer A (a). Therefore, It is suggested that the polymerization proceeds through the rings containing the $\mathrm{NH}_{2}$ group, and that polymer $\mathrm{A}$ has the polyaniline-like structure.

On the other hand, in the spectrum of polymer B (b), this band remains. It is not likely to be because of polymer chain end since no absorption from amino groups in the spectrum of polymer $\mathrm{B}$. It suggests that the bonding manner between monomer units in polymers $\mathrm{B}$ is different from that of polymer A. But the details are unknown at the present time.

The peaks attributed to quinone groups were observed at $1607 \mathrm{~cm}^{-1}$ for the monomer and the polymers, respectively.

3. 2. 1 Electrochemistry of Monomers The cyclic voltammetric response of a $c a .2 \mathrm{mM}$ (saturated) monomeric $5-\mathrm{AQ}$ acetonitrile solution containing $0.1 \mathrm{M}$ tetraethylammonium perchlorate (TEAP) at Pt plate electrodes is illustrated in Fig. 2(a). In the potential range from -1.65 to $0.0 \mathrm{~V}$ vs. $\mathrm{Ag} / \mathrm{AgCl}$, there are well separated two reversible couples with reduction peaks at -0.79 and $-1.24 \mathrm{~V}$ vs. $\mathrm{Ag} / \mathrm{AgCl}$, and oxidation peaks at -0.72 and $-1.16 \mathrm{~V}$ vs. $\mathrm{Ag} / \mathrm{AgCl}$, respectively. Similar

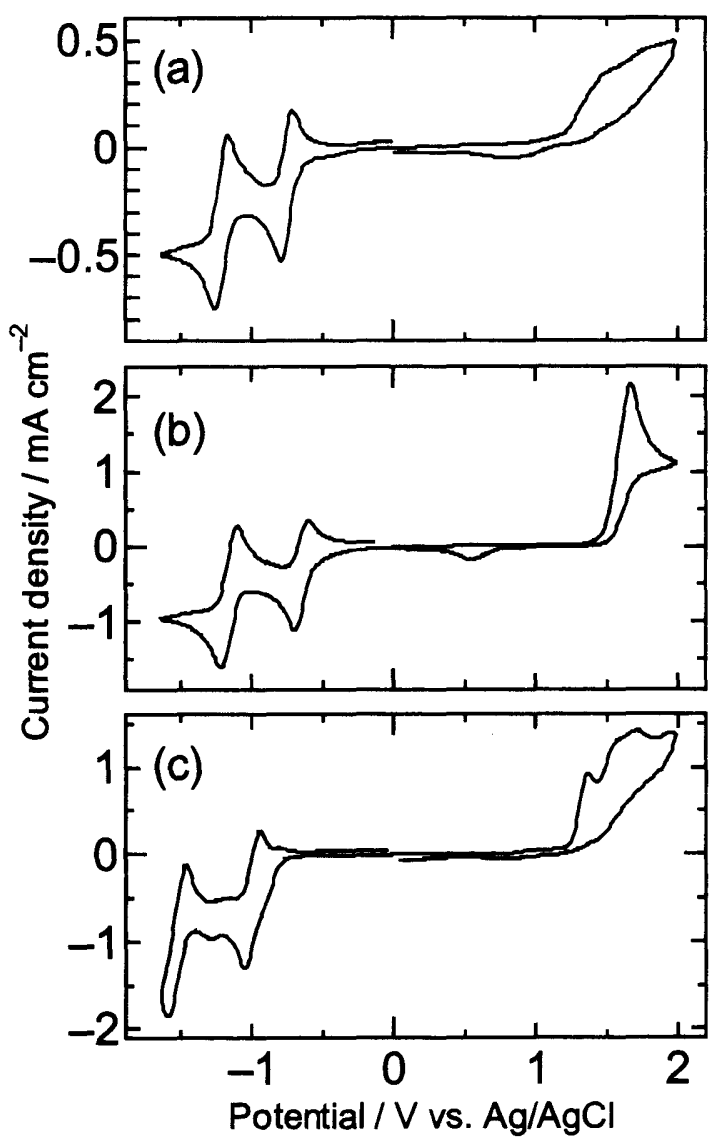

Fig. $2 \mathrm{CVs}$ of various monomers: (a) ca. $2 \mathrm{mM}$ (saturated) monomeric 5-AQ; (b) $4 \mathrm{mM}$ quinizarin; (c) $4 \mathrm{mM}$ aminoanthraquinone acetonitrile solution at $\mathrm{Pt}$ plate electrodes at 50 $\mathrm{mV} / \mathrm{s}$ of scan rate. The Supporting electrolytes were $0.1 \mathrm{M}$ tetraethylammonium perchlorate (TEAP). 
redox peaks exist in the cyclic voltammograms of anthraquinone derivatives such as Quinizarin and Aminoanthraquinone shown in Figs. 2(b) and 2(c), respectively. Their two redox couples are attributed to quinone/ semiquinone anion $\left(\mathrm{Q}^{\%} / \mathrm{Q}^{-}\right)$redox couple and semiquinone anion/quinone dianion $\left(\mathrm{Q}^{-} / \mathrm{Q}^{2}\right)$ redox couple, respectively.

In the potential range from 0.0 to $+2.0 \mathrm{~V}$ vs. $\mathrm{Ag} / \mathrm{AgCl}$, an irreversible anodic wave was observed at over $c a$. $+1.2 \mathrm{~V}$ vs. $\mathrm{Ag} / \mathrm{AgCl}$ in Figs. 2 (a) and 2(c). In contrast, no anodic wave is observed around at $+1.3 \mathrm{~V}$ vs. $\mathrm{Ag} /$ $\mathrm{AgCl}$ in the voltammogram of quinizarin having no aromatic amine group (quinizarin has the irreversible anodic peak at $+1.72 \mathrm{~V}$ vs. $\mathrm{Ag} / \mathrm{AgCl}$ ) in Fig. 2(c). Therefore, the irreversible anodic wave higher than $+1.2 \mathrm{~V}$ vs. $\mathrm{Ag} /$ $\mathrm{AgCl}$ is most probably due to the aromatic amine portion of the 5-AQ molecule.

The polymerization was possible with $\mathrm{LiClO}_{4}$ as a supporting electrolyte.

3. 2. 2 Polymer growth Figure 3(a) shows a cyclic voltammogram of saturated 5-AQ $(c a .2 \mathrm{mM})$ on a $\mathrm{Pt}$
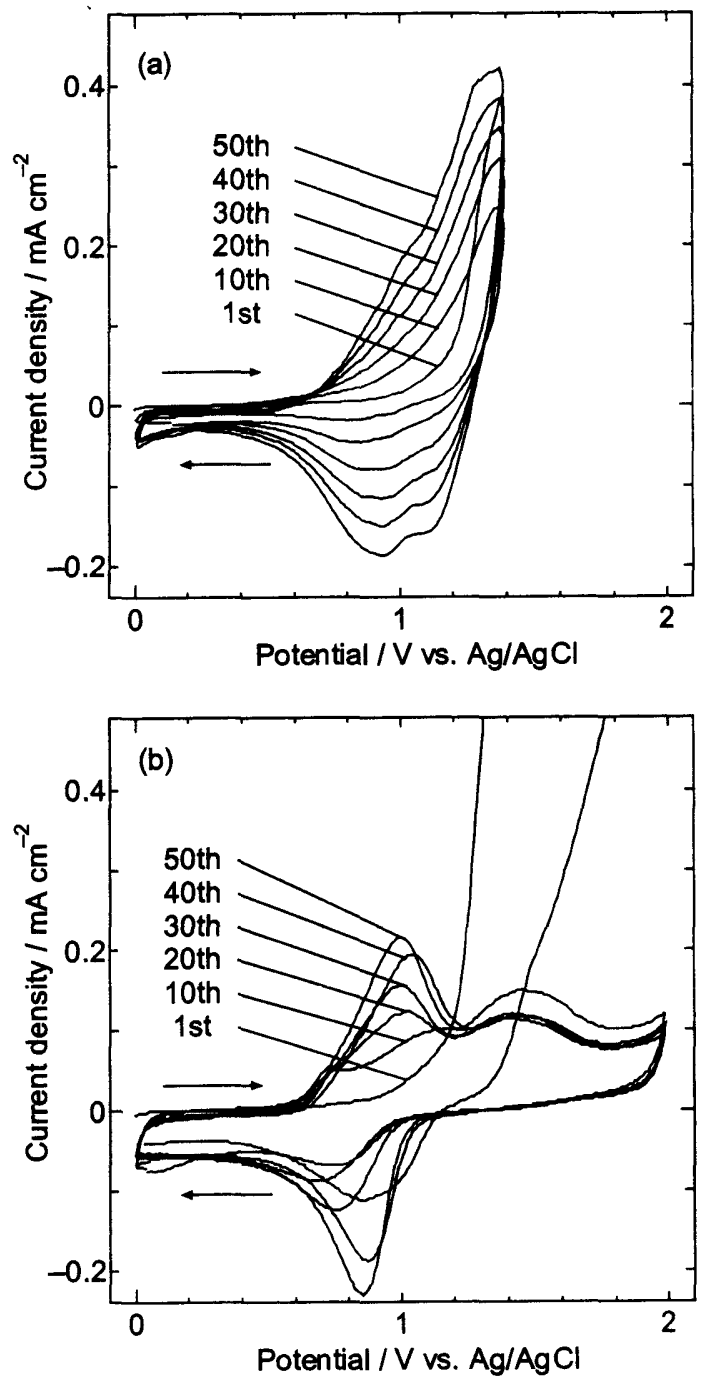

Fig. $3 \mathrm{CVs}$ recorded during poly(5-AQ) growth from $2 \mathrm{mM}$ 5-AQ containing $0.1 \mathrm{M}$ TEAP acetonitrile solutions at a scan rate of $50 \mathrm{mV} / \mathrm{s}$ on Pt plates: (a) in the potential range of 0.0 to $+1.4 \mathrm{~V}$ vs. $\mathrm{Ag} / \mathrm{AgCl}$; (b) in the potential range of 0.0 to $+2.0 \mathrm{~V}$ vs. $\mathrm{Ag} / \mathrm{AgCl}$. electrode during the polymer A growth. The potential was scanned between 0.0 and $+1.4 \mathrm{~V}$ vs. $\mathrm{Ag} / \mathrm{AgCl}$; the scan rate was $50 \mathrm{mV} / \mathrm{s}$; the medium was acetonitrile containing 0.1 M TEAP. At a first scan, an irreversible anodic peak corresponding to the oxidation of aromatic amine monomer was observed. During the successive potential scans, this anodic peak height was decreased, and a new redox couple was appeared around at $+1.0 \mathrm{~V}$ vs $\mathrm{Ag} / \mathrm{AgCl}$. This new redox couple was related to the polymer produced on the electrode and the peak height grew during the successive scans. This indicates that conductive polymer film was produced. After 50 cycles, a blue-violet adherent film was obtained on the Pt plate.

5-AQ monomer is hardly polymerized by constant potential method. It has been reported that monoaminoanthraquinone like 1-aminoanthraquinone, which has the large anthraquinone group and the single amino group, was less efficient in forming films than 5 aminonaphthoquinone and 1,5-diaminoanthraquinone. ${ }^{3)}$ The electro- polymerization of $5-\mathrm{AQ}$ was slower than that of 1-aminoanthraquinone, which is probably ascribed to that the quinone moiety of $5-\mathrm{AQ}$ is larger than that of 1 aminoanthraquinone. As another reason, it is considered that electrooxidized monomer cannot polymerize to fully oxidized polymer terminal.

Figure 3(b) shows a cyclic voltammogram of saturated 5 -AQ (ca. $2 \mathrm{mM})$ on a $\mathrm{Pt}$ electrode during the polymer B growth. The potential was scanned between 0.0 and $+2.0 \mathrm{~V}$ vs. $\mathrm{Ag} / \mathrm{AgCl}$; the scan rate was $50 \mathrm{mV} / \mathrm{s}$; the medium was acetonitrile containing $0.1 \mathrm{M}$ TEAP. The growth of Polymer B was slower than that of polymer A. But the redox response of polymer $B$ was better than that of polymer A.

\section{2. 3 Electrochemical properties of poly(5-AQ)}

Cyclic voltammetry for the polymers were performed in acetonitrile containing $0.1 \mathrm{M}$ TEAP and no monomer. Figures 4(a) and 4(b) show the cyclic voltammograms of the polymer $A$ and polymer $B$ which were electropolymerized as shown in Figs. 3(a) and 3(b), respectively. The potential was swept between 0.0 and $+1.0 \mathrm{~V}$ vs. $\mathrm{Ag} / \mathrm{AgCl}$ at a scan rate of $50 \mathrm{mV} / \mathrm{s}$. Redox responses were observed in this voltammograms, and the shapes of voltammograms are similar to each other. They represent the redox system of the polyaniline backbone. These polymers have also good cycleability as shown in Fig. 6. The capacity of polymer A was nearly constant especially af ter 5th cycle as shown in Fig. 6(a).

As is shown in Figs. 5(a) and 5(b), the successive potential scans between 0.0 and $+1.4 \mathrm{~V}$ vs. $\mathrm{Ag} / \mathrm{AgCl}$ at a scan rate of $50 \mathrm{mV} / \mathrm{s}$ led to the diminishing of heights of the redox peaks. The reduction of the peak height is attributed to the degradation of fully oxidized quinoid form of the polyaniline-like structure. ${ }^{10\}}$ As with polyaniline, it has been reported that if the potential exceeds $+1.2 \mathrm{~V}$, polymer stability decreases due to overoxidation. ${ }^{9,11-14,17-18)}$ The CV shape of polymer B differs from that of polymer $A$. This suggests that the structures of polymer A and polymer B are not same. This corresponds with the results obtained from FTIR spectra as shown in Fig. 1. The cycleability are also shown in Figs. 

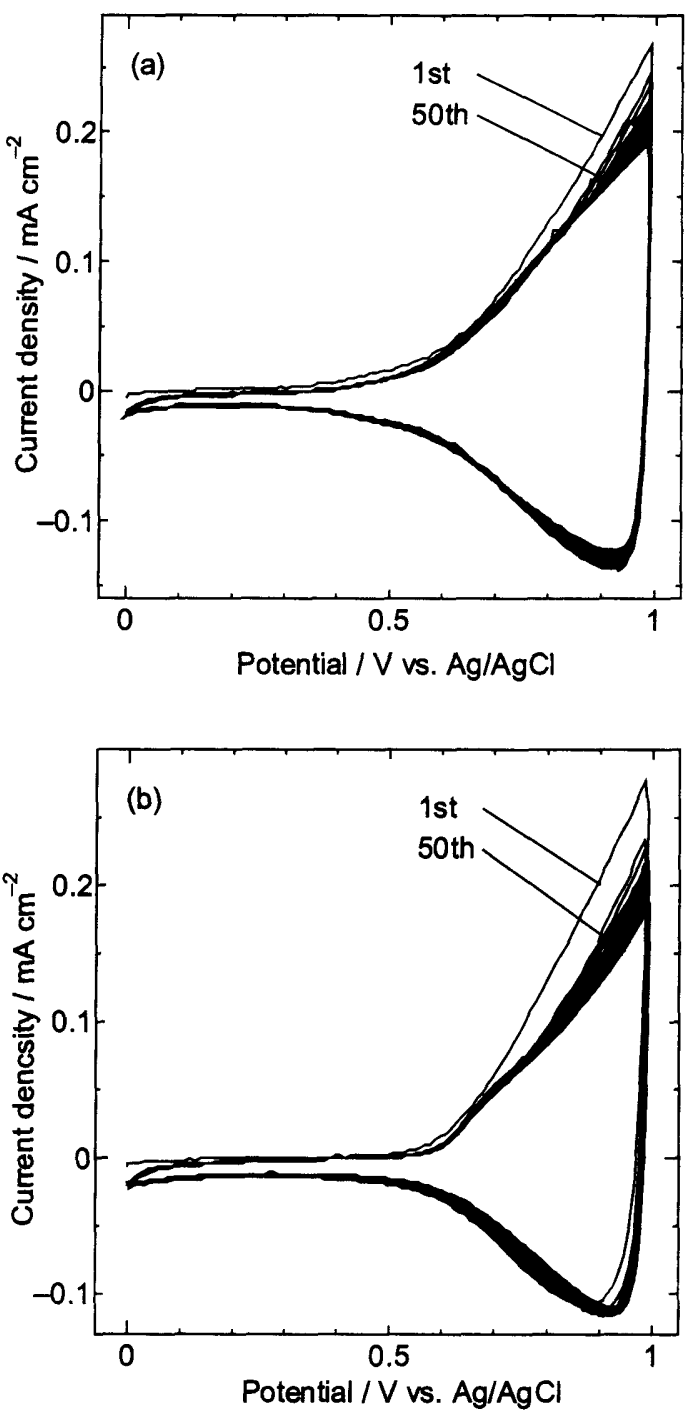

Fig. $4 \mathrm{CVs}$ of Pt electrodes coated with polymers: (a) polymer A; (b) polymer $\mathrm{B}$ in acetonitrile containing 0.1 M TEAP at a scan rate of $50 \mathrm{mV} / \mathrm{s}$ in the potential range of 0.0 to $+1.0 \mathrm{~V}$ vs. $\mathrm{Ag} / \mathrm{AgCl}$.

6 (c) and 6(d).

When this polymer was swept between 0.0 and -1.65 $\mathrm{V}$ vs. $\mathrm{Ag} / \mathrm{AgCl}$ in acetonitrile containing $0.1 \mathrm{M}$ supporting electrolyte (TEAP or $\mathrm{LiClO}_{4}$ ) and no monomer, only an irreversible cathodic wave was observed with a green elute from the working electrode, and no anodic wave was observed. It is indicated that the polymer is decomposed in this potential range. Such decomposition in the negative potential range was not reported in neither poly (1-amino-9,10-anthraquinone $)^{10)}$ nor poly(1,5-diamino-9,10anthraquinone) ${ }^{3,7)}$ Although the details of mechanism are not clear, this decomposition in this potential range may have relation to the quinizarine structure.

The redox peak height of this polymer in acetonitrile containing $0.1 \mathrm{M} \mathrm{LiClO}_{4}$ was higher than that in acetonitrile containing $0.1 \mathrm{M}$ TEAP. The applications to metal ion sensor etc. can be expected.

\section{Acknowledgement}

The authors thank a grant from the NITECH 21st Cen-
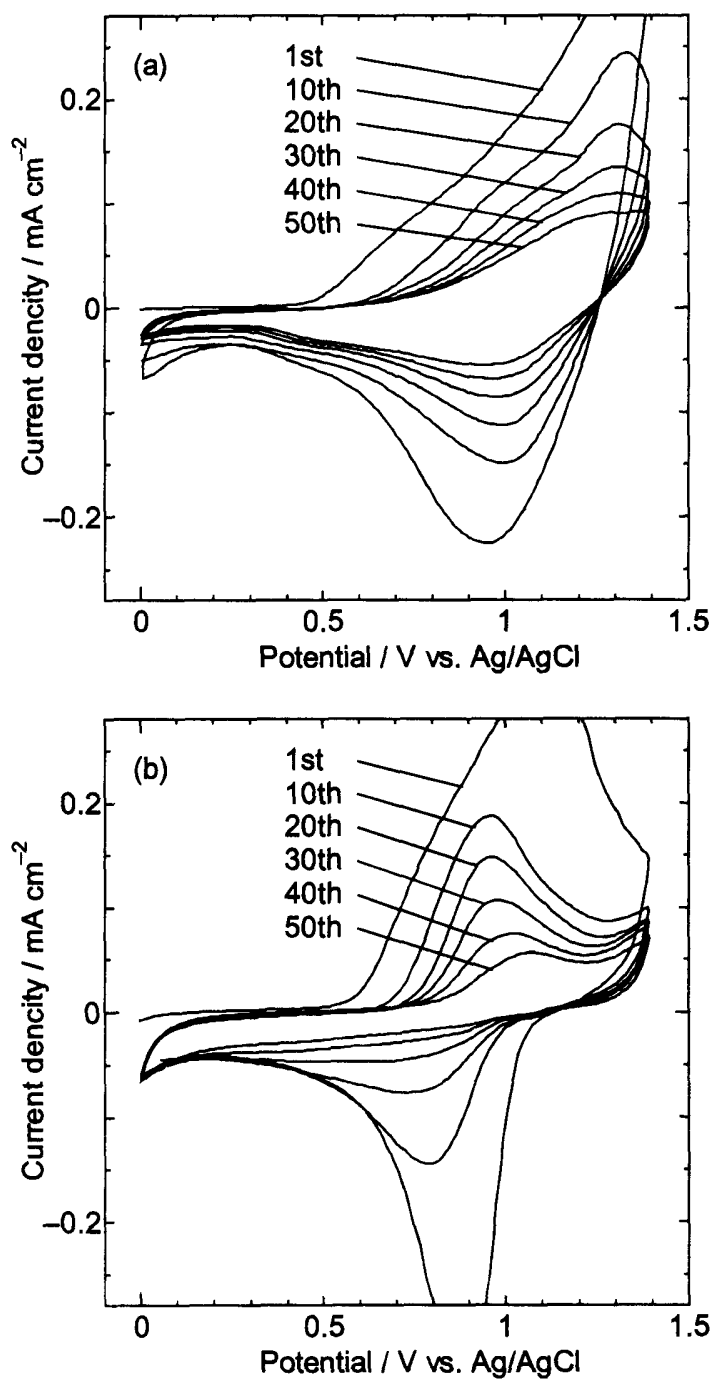

Fig. $5 \mathrm{CVs}$ in acetonitrile containing $0.1 \mathrm{M}$ TEAP at a scan rate of $50 \mathrm{mV} / \mathrm{s}$ in the potential range of 0.0 to $+1.4 \mathrm{~V}$ vs. $\mathrm{Ag} / \mathrm{AgCl}$ for $\mathrm{Pt}$ plate electrodes coated with (a) polymer $\mathrm{A}$; (b) polymer $\mathrm{B}$.

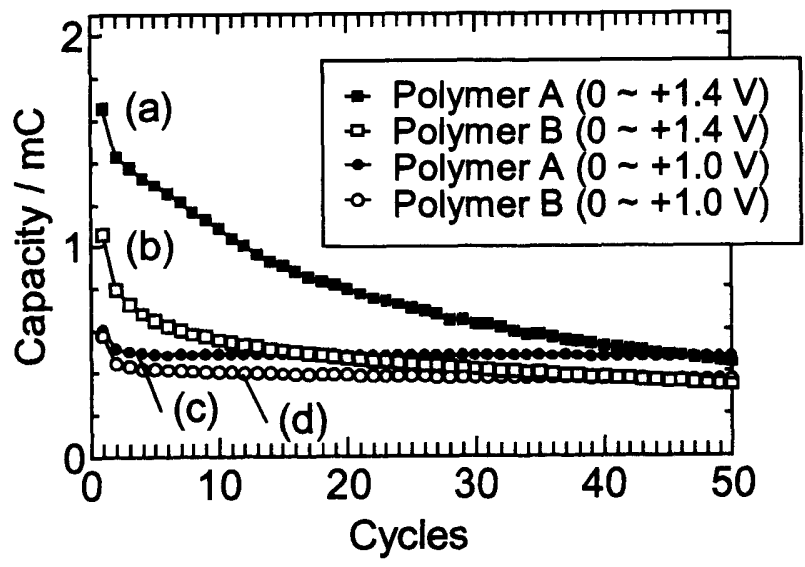

Fig. 6 Charge capacity plot to cycle number. The polymers were swept in the potential range of 0.0 to $+1.4 \mathrm{~V}$ for polymer A (a) and for polymer B (b), or 0.0 to $+1.0 \mathrm{~V}$ for polymer A (c) and for polymer B (d) at a scan rate of $50 \mathrm{mV} / \mathrm{s}$ in acetonitrile containing $0.1 \mathrm{M}$ TEAP. The electrode area was $0.5 \mathrm{~cm}^{2}$. 
tury COE Program for Environmental Ceramics for financial support.

\section{References}

1) M. v. Stackelberg, in Methoden der Organischen Chemie (Houben-Weyl), Georg Thieme Verlag, Stuttgart, III/2, p. 255 (1955).

2) E. S. Matveeva, Synth. Met., 83, 89 (1996).

3) V. K. Gater, M. D. Liu, M. D. Love, and C. R. Leidner, J. Electroanal. Chem. 257, 133 (1988).

4) Y. Matsuda, M. Morita, M. Ishikawa, F. Anami, K. Adachi, and H. Tajima, JP Patent, 10154512 (1998).

5) W. Wang, T. Yamaguchi, K. Takahashi, and T. Komura, Denki Kagaku (presentry Electrochemistry), 66, 1032 (1998).

6) M. C. Pham, B. Piro, E. A. Bazzaoui, M. Hedayatullah, J.C. Lacroix, P. Novák, and O. Hass, Synth. Met., 92, 197 (1998).

7) Katsuhiko Naoi, Shunzo Suematsu, and Ari Manago, J. Electrochem. Soc., 147, 420 (2000).

8) A. G. BAYER, Fr. Patent, 1539559 (1968).
9) A. Kabumoto, K. Shinozaki, K. Watanabe, and N. Nishikawa, Synth. Met., 26, 349 (1988).

10) K. M. Ismail, Z. M. Khalifa, M. A. Azzem, and W. A. Badawy, Electrochim. Acta, 47, 1867 (2002).

11) P. A. Kilmartin and G. A. Wright, Synth. Met., 104, 145 (1999).

12) D. Gonçalves, L. H. C. Mattoso, and L. O. S. Bulhões, Electrochim. Acta, 39, 2271 (1994).

13) A. G. Bedekar, S.F. Patil, R.C. Patil, and C. Agashe, J. Phys. D: Appl. Phys., 27, 1727 (1994).

14) A. G. Bedekar, S. F. Patil, R. C. Patil, and K. Vijayamohanan, J. Mater. Chem., 5, 963 (1995).

15) R. M. Silverstein, G. C. Bassler, and T. C. Morrill, Spectrometric Identification of organic Compounds $5^{\text {th }}$ Edition, John Wiley \& Sons, Inc. (1991).

16) P. Chandrasekhar, Conducting polymers, Fundamentals and Applications: A Practical Approach, Kluwer Academic Pub., p.388 (1999).

17) D. E. Stilwell and S. Park, J. Electrochem. Soc., 135, 293 (1988).

18) T. Kobayashi, H. Yoneyama, and H. Tamura, J. Electroanal. Chem., 177, 293 (1984). 